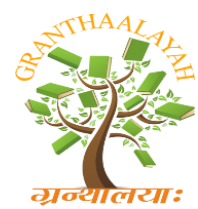

INTERNATIONAL JOURNAL OF RESEARCH GRANTHAALAYAH

A knowledge Repository

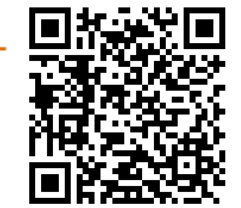

Management

\title{
QUALITY OF HUMAN RESOURCE INFORMATION SYSTEMS AT COMMERCIAL BANK OF ETHIOPIA (A CASE STUDY OF DESSIE DISTRICT AT DESSIE, ETHIOPIA)
}

\author{
Dr. Ponduri SB ${ }^{* 1}$ \\ ${ }^{* 1}$ Associate Professor, Department of Management, College of Business and Economics, Wollo \\ University, Dessie, ETHIOPIA
}

\begin{abstract}
Information systems are the back bones of every organization in the modern era of business management. It is inevitable for these organizations to use information system so as to face the global competition and survive in the market. No organization and country is an exception to it. Human resources management is one of the crucial departments in every organization that uses management information systems. HR information systems help to identify potential employees, maintaining complete records on existing employees and creating programs to develop employee skills and talents. This helps the top level management to identify the future manpower requirements in order to meet the long term goals and objectives, middle level management to monitor, analyze the recruitment, promotion, allocation and compensation and lower level management to track the recruitment and placements. HRIS can also support various human resource practices such as workforce planning, staffing, salary, compensation forecasts, budgets and industrial relations. The current research is mainly focused on human resource information systems (HRIS) perception and effectiveness. The required data was collected through primary and secondary sources. The research approach is both quantitative and qualitative. A sample of 100 respondents working in different department of commercial bank of Ethiopia, Dessie district were taken for the study. The findings of this research results in employees are satisfied with salary, job position, promotion scheme, and working environment but worried about the system about information sharing of human resource and their difficulty to store, retrieve, share and maintain information.
\end{abstract}

Keywords:

Human Resource Information (HRI), Human Resources (HR), Information systems, Potential skills, Talents, data bases.

Cite This Article: Dr. Ponduri SB, "QUALITY OF HUMAN RESOURCE INFORMATION SYSTEMS AT COMMERCIAL BANK OF ETHIOPIA (A CASE STUDY OF DESSIE DISTRICT AT DESSIE, ETHIOPIA)" International Journal of Research - Granthaalayah, Vol. 4, No. 4 (2016): 31-41. 


\section{INTRODUCTION}

Human resource information system (HRIS) is defined as an "Integrated system used to gather, store and analyze human resources information". It comprises of databases, computer applications, hardware and software necessary to collect, record, store, manage, deliver, present and manipulate the data for human resources function". It can perform number of functions from simple storage and communication of information to more complex transactions. The ranges of functions undertaken by HRIS are increasing day by day. The use of HRIS can provide a number of benefits not only to the human resource function but also to line managers and the wider organizations. It helps the human resource professionals to become more efficient and strategic partners of the top management by providing information for decision making. Peoplemanagement activities will liberate human resource specialists to perform more strategic activities. According to Ulrich as one of the strategic partners, the human resource manager derives benefit from HRIS to disseminate and execute the strategy within the organization. These systems enable employees to manage their own human resources. In addition to the former operational role, human resource professionals can also act as a competency manager by arranging the right people to the right positions in the right time with their new strategic architecture. Due to its vast usage many organizations have adopted HRIS to assist human resources operations. HRIS must be customize and satisfy the needs of the organization and its users in order to be successful.

\section{OBJECTIVE OF THE STUDY}

- To study the quality of Human Resource Information system's in Ethiopian banks.

- To evaluate the current HRI meets the current expectation of the bank.

- To identify the modules implemented and the support extended by IT department.

- To observe the post implementation advantage of HRIS in banks.

\section{SIGNIFICANCE OF THE STUDY}

Human resource information system has an important role in every organizations success. Organizations need to maintain human resource data for accomplishment of its goals. The current study mainly focused to know the problems face in human resource in handling its data at commercial bank of Ethiopia, Dessie district level and to investigate a solution for it. Organizations need to maintain reliable information for human resources for the empowerment of its staffs. This makes the organizations to take necessary security measures for the data access, effective storage, easy and fast retrieval are the main roles.

\section{SCOPE OF THE STUDY}

The study is confined to Commercial Bank of Ethiopia, Dessie district. The focus is on the existing manual system used by the bank for filing of personal employee profile, information sharing, data storing and retrieval problem are the major focus areas of the study. Personal employee profile includes full name, job title, and experience in years, place of assignment, employee category, salary, education level, marital status and others. This study mainly focuses 
on assessing the human resource information system practices adopted by the company and their effect in increasing organizational efficiency.

\section{LITERATURE REVIEW}

In order to find the research gaps in the available research the researcher has reviewed various researches available for the last 15 years. Survey by IMA (2002) survey conducted by the Institute of Management and Administration in the year 2002 indicated that the biggest problems in managing HRIS include: lack of staff, lack of budget, problems with time management, need to work with other departments and lack of information technology support.

Beckers and Bsat (2002) In order to satisfy from all walks of life banks need to have efficient manpower this can be possible only by offering quality information system that helps for easy sharing of information, store and retrieve. HRIS should change with changing times. To strengthen HRIS changes should be done to mental and social outlook of employees, customers and their needs can be identified. These needs should be satisfied accordingly. They also pointed out pointed out five reasons for the need of HRIS in companies. They are Increase competitiveness by improving HR operations, produce large number of variety of related reports, shift the focus of human resources from the processing of transactions to strategic human resource management, develop employee participate HRIS and reengineer the entire human resource functions of companies. Hendrickson R. Anthony, (2003): using HRIS is an opportunity for HR professionals in order to become strategic partners with top management. This would help by allowing human resource function to become more efficient and providing better information for decision-making. But the question remains if HRIS has fulfilled its promise. Nah et al., (2003) considered HRIS is an integral part of Enterprise Resource Planning (ERP) system and thus supports a process-oriented view of organization and standardizes business processes across the enterprise. Lengnick- Hall and Moritz (2003) prompts HRIS is to be implemented in three different levels. They are publishing information, automation of transaction, transform human resource as a strategic partner with the line of business. Mayfield, Mayfield and Lunce (2003) Therefore, companies are reluctant to implement HRIS, unless they are convinced with the benefits that information system would bring to their organizations. The common benefits of includes enhancement in executive decision making, employee training, technology usage, interdepartmental integration and better reporting structures. Moreover, Burbach \& Dundon (2005) conducted a study aimed to assess the strategic potential of HRIS to facilitate people management activities in 520 organizations in the republic of Ireland. They found that foreign owned large organizations adopt HRIS largely than smaller Irish owned organizations. They also found that HRIS technologies are used for administrative rather than strategic decision-making purposes. Beadles, Lowery \& Johns, (2005) the use of HRIS has been advocated as an opportunity for human resource professionals to become strategic partners with top management. It allows HR function to become more efficient and to provide better information for decision making. Ngai and Wat, (2006) the basic purpose of HRIS is insurance to an adequate information base for decision making process, development of a selection program, education, training, promotion, career planning, communication, analysis of working abilities of employees', complying working claims with individual skills. They also conducted a survey for the implementation of HRIS in Hong Kong organizations, they found that the greatest benefits to the implementation of HRIS was the quick response and access to information that it brought while the greatest barrier was the insufficient 
financial support. Poloski, (2007) quality HRIS is mainly base for achieving organizational goals due to the above information quoted and stated. Since human resource is organization's most valuable asset, satisfied employees are pre condition for satisfied customer. Arneri E et al., (2007) managing HRIS include responsibility for design, HRIS presents a field of intersection between human resource management, information and communication technology. Due to its interdisciplinary character in many cases it is yet unclear. Key persons responsible for basic design of HRIS with adequate level of knowledge in the organization the compliance with legislation. It should also consider all specific claims in order to eliminate compliance risk, internal policies, besides general "roof" policies that regulate information system management, specific policies. This is especially important because of the sensitivity of the data that HRIS encompasses. Ulrich (2007\& 2009) HRIS as one of the strategic partners, the HR manager derives benefit from it to disseminate and execute the strategy within the organization. These systems enable employees to manage much of their own HR administrative work. They can take care of many routine transactions, because automated systems don't keep office hours. Ngai et al, (2008) is used to gather and maintain the data that describe human resources transforming data into information and then reporting the information to users. Haag \& Cummings, (2008) HRIS can also support various human resource practices like work force planning, staffing, compensation and salary forecasts. Organizations must treat information as any other resource or asset. It must be organized, managed and disseminated effectively for the information to exhibit quickly and qualitatively. Kulik \& Perry (2008) the increased use of web technology to deliver human resources will leave human resource specialists more time for strategic decision making than outsourcing of people-management activities will liberate human resource specialists to perform more strategic activities. Bajgorie and Moon (2009) ERP system is a widely accepted solution to achieve an integrated enterprise information system because it integrates key functions of an organization, such as accounting, finance, human resources and support functions into an universal database. Laudon and Laudon (2009) the information system field is arguably one of the fastest charging and dynamic of all business process, because information technologies are among the most important tools for achieving business firm's key objectives. Staudinger (2009) during the 1990s, along with the adoption of more complex HR practices focused on a company's overall performance goals, HRIS correspondingly evolved in to more sophisticated information expert systems. Keim \& weitzel (2009) information technology during the past decade drastically changed the human resource functions, providing support for payroll, attendance management, enhance recruitment functions, on line advertisements, CV's database, and different forms of electronic applications. Ostermann, Staudinger \& Staudinger (2009) HRIS is thought to contribute to overall business performance by fulfilling or at least supporting the tasks of data storage and retrieval of serving as primary administrative support tools of reporting and statistics as well As of program monitoring. Parry (2009) actually HRIS is directed towards the HR department itself but the use of HRIS can provide a number of Benefits not only to the HR function, but also line managers, and the wider organization. Gürol, Wolff $\boldsymbol{\&}$ Ertemsir (2010) in addition to their former operational role, human resource professionals can also act as a competency manager by arranging the right people to the right positions in the right time with their new strategic architecture role. Singh et al. (2011) HRIS has emerged as an important interdisciplinary tool to achieve vital organizational human resource objectives. It is applied in administration, salary administration, leave/absence recording, skill inventory, medical history, performance appraisal, training and development, human resource planning, recruitment, career planning, negotiation. Dr. Harman Preet Singh, Dr. Sunita Jendel, Sekh 
Abdul Samine (2011) in recent times, the financial as well as non-financial processes of banks has undergone significant transformation. The manual system adopted by the banks was the cause of procedural delays, out dated as well as inaccurate information, improper documentation, higher expense of strong files and their safety. It has transformed banks financial as well as nonfinancial processes from manual to automatic computerized systems. Banks are able to integrate different human resource functions by using third generation of feature rich, broad based and self-contained HRI. The third generation HRI is much more than a mere data repository and has hastened the emergency of strategic HRM in banks of developing countries. Due to strategic HRM, banks' HR professionals are encouraged to innovate their IT usage become more effective, HR department is emerging as an information center, internal consultant, and charge agent, service provider, cost manager, business partner, Facilitator and consultant. Noor \& Razali (2011) HRIS plays an important role for any organization to effectively manage its human assets. Many Organizations have adopted HRIS to assist their daily human resources operations. HRIS must align and satisfy the needs of the organization and its users in order to be successful.

\section{RESEARCH METHODOLOGY}

Descriptive research is used in the study. The purpose of the study is to describe the state of affiras, expain the charectaristics and depth of the existing problem. Concerninig, the reaserch approach that the researcher will be employed is both qualitative and quantitative approaches. The qualititave approach will be used for the subjective assessment of attitudes, opinions and perception of staff members. On the other hand, quantitative research approach involves the generation of data in quantitative form which can be subjected to quantitative analysis to a data base from which to questionnaire collected from the respondents.

\section{POPULATION \& SAMPLE}

The target population is clerical and non-clerical staff of all commercial banks located in Dessie district, Ethiopia. Out of the available population a sample of 100 members are selected by using non-probability sampling.

\section{DATA COLLECTION METHOD}

The data for the research consists of both primary and secondary. The primary data was collected by using a structured questionnaire consists of both open ended and closed ended questions. Likert scale 5 point rating scale is used to assess the employee perception towards the human resource information system. In order to support the primary data, secondary data also collected from $\mathrm{CBE}$ journals, books, magazines, articles of referred and non-referred, websites of the related. In addition to this interviews also taken from the higher officials of the bank.

\section{DATA PROCESSING, ANALYZING AND INTERPRETING TOOL}

Generally, the related demographic factor is assessed through descriptive analysis like mean using seniority, educational qualification and age factor in implementing and keeping quality human information system in Commercial Bank of Ethiopia, Dessie district. 


\section{VALIDITY \& RELIABILITY}

In this study, validity \& reliability was taken into consideration. The questionnaire is constructed by the researcher, it is designed on the basis of the researcher's needs in relation to the selected topic and so brings advantages in the sense that it measures exactly what the researcher intends to measure. The researcher therefore does not need to depend on other researcher's information. For example problem areas and relevance of the items included in the questionnaire. Further descriptive, interpretative, and theoretical validity were taken into consideration. Thorough literature review in the study area was conducted carefully before taking on the research. This enabled theories and the questions in the questionnaire to be identified. Theories and themes are well supported by the findings. The questions in the questionnaire to be designed by taking into consideration the issues related to the problem and goals of the study and theories on the subject. It is therefore believed that the responses and results from this study are reliable.

\section{DATA ANALYSIS AND DISCUSSION}

In order to examine the research hypotheses, the data collected through the five point scale of measurement, Distributed to all staffs of Commercial bank of Ethiopia, Dessie District through five scale measurement (Scale: SA= Strongly Agree A=Agree N=Neutral DA=Disagree SDA=Strongly Disagree) . The respondents of this study were asked to give information about their gender, age, educational level, and Current position. From the results appear in Table 1 below, the number of male respondents is more than the number of female ones.

Table 1: Respondents' Demographic Profile

\begin{tabular}{|l|l|l|l|}
\hline Variables & Response & Frequency & Percentage \\
\hline Gender & Male & 84 & 84 \\
\hline & Female & 16 & 16 \\
\hline Education & Diploma & 45 & 45 \\
\hline & Undergraduate & 54 & 54 \\
\hline & MBA & 01 & 01 \\
\hline Position & Manager & 35 & 35 \\
\hline & Officer & 17 & 17 \\
\hline Seniority & Other & 48 & 48 \\
\hline & $<10$ yrs & 69 & 69 \\
\hline & $10-20$ yrs & 26 & 26 \\
\hline
\end{tabular}

(Source: own survey 2015)

Employee from different department participated to the research $(n=100)$.the social demographic participants of the employees are as follows. $16(16 \%)$ are female and $84(84 \%)$ are male participated in the research the educational background of the participants are 45(45\%) are Diploma and 54(54\%) are undergraduate degree and 1(1\%) MBA .To seize the above result most of the participants are male and most others are undergraduate who have Bachelor so they easily understand the human resource information in the district. On the basis of seniority most of the participants are less than 10 year's it covers $69 \%$. whereas in terms of position $17 \%$ are officers working in different department in the commercial bank of Ethiopia ,Dessie district so the above 
variables are indicators(measures)how the human resource information system are implemented in Dessie district. This research was exploratory and primarily descriptive in nature. The intent was to discover whether the Commercial Bank of Ethiopia, Dessie District Staffs perceived that human resource information were proving beneficial in regard to its strategic impact on the organization. The survey items are contained in Figures. The results of the survey are contained in Tables shows. The survey items were divided into categories concerning satisfaction with the HRI (Table 2); the impact of the HRI on HR processes (Table 3); time savings due to the HRI (Table 4); and the strategic impact of the HRI and the impact of the HRI on the role of the HR function in the organization (Table 5). We had a relatively small sample size as mentioned above. Therefore, we used frequency tables to measure the percentage of favorable responses to a series of questions assessing Commercial bank of Ethiopia, Dessie District Staffs employee HRI. The expressed results are the percentage of respondents for each item who either agreed or strongly agreed with the statement.

Table 2: Satisfaction with HRI

\begin{tabular}{|l|l|}
\hline Items & \% agreed \\
\hline Overall I am satisfied with our HRI. & $\mathbf{3 7 . 5}$ \\
\hline $\begin{array}{l}\text { The employees of HR department appear to be satisfied with } \\
\text { our HRI. }\end{array}$ & $\mathbf{4 5}$ \\
\hline Our HRI has met our expectations. & $\mathbf{4 4}$ \\
\hline Our HRI could be better utilized & $\mathbf{1 0 0}$ \\
\hline
\end{tabular}

(Source: own survey 2015)

The above displays the satisfaction of the staff with the HRI. The results show that, less than half about were satisfied with the HRI, and a similar number of respondents concurred that the system was up to their expectation. The percentage of people actually being satisfied was just above one-third, and all employees agreed that their HRI could be put to better use. These studies indicated that the satisfaction with regards to HRI was mixed. And almost all of the respondents felt that it could be better utilized. These results do not take into consideration whether the staff had been trained properly in the use of HRI, nor were they properly briefed about the systems utility.

Table 3: HR Process

\begin{tabular}{|l|l|}
\hline Items & \% agreed \\
\hline Our HRI has improved the recruitment process & $\mathbf{4 2}$ \\
\hline Our HRI has improved the training process. & $\mathbf{3 6}$ \\
\hline Our HRI has improved the data input process. & $\mathbf{4 0}$ \\
\hline Our HRI has improved the data maintenance process & $\mathbf{4 4}$ \\
\hline Our HRI has decreased paper work. & $\mathbf{3 6}$ \\
\hline
\end{tabular}

(Source: own survey 2015)

With regard to HRI contribution in streamlining various HR processes, nearly $40 \%$ respondents agreed that administrative processes such as decrease in paperwork, forecasting staffing need and data maintenance had improved but the remaining $60 \%$ of the participants say the current HRI did not help them to implement the administrative process. So it is considerable impact on training, input process, maintaining information and to reduce paper work. 
Table 4: Time Savings

\begin{tabular}{|l|l|}
\hline Items & \% Agreed \\
\hline Our HRI has decreased the time spent on recruiting & $\mathbf{2 5}$ \\
\hline Our HRI has decreased the time spent on training & $\mathbf{3 2}$ \\
\hline Our HRI has decreased the time spent on inputting data. & $\mathbf{3 6}$ \\
\hline $\begin{array}{l}\text { Our HRI has decreased time spent on communicating information in } \\
\text { Organization. }\end{array}$ & $\mathbf{4 5}$ \\
\hline
\end{tabular}

(Source: own survey 2015)

Time saving is one of the barometers against which the efficiency of any information system can be gauged. This study showed that $34.5 \%$ of the respondents believed that the system had a negative impact on some administrative functions such as time spent on recruiting, routine staff decisions, processing of paper work, and error correction. However, most others $65.5 \%$ believed that it didn't help in improving the communication of information within the organization and much time spent on training, recruiting and inputting data.

Table 5: Strategic Impact and Role of HR Items

\begin{tabular}{|l|l|}
\hline Items & \% Agreed \\
\hline $\begin{array}{l}\text { The information generated from our HRI has added value to the } \\
\text { organization. }\end{array}$ & 45 \\
\hline Our HRI has promoted our Organization Comparative advantages. & 42 \\
\hline
\end{tabular}

(Source: own survey 2015)

In terms of whether HRI has enhanced the strategic role of the HR department, 43.5\% respondents believed that HRI increased the importance of HR department and made it a strategic partner, whereas, 56.5\% didn't believe that HRI improved the strategic decision-making of the top administrators and it needs more improvement. To conclude the above point, most of the employee dissatisfied with the current application of human resource information by any means. So it is difficult to achieve its strategic goal of the bank, improve human resource practices and human resource process. As most senior staff expressed that the human resource practice and data input process in Commercial Bank of Ethiopia, Dessie District needs further improvement to achieve banks target easily within the specified period time. Especially on the area of time spent on recruiting, training, data input process and communication as most respond ants respond more focus is needed.

\section{CONCLUSION AND RECOMMENDATION}

HRI has a very wide scope in banks of developing countries. It is applied in personnel administration, salary administration, leave of absence recording, skill inventory, medical history, performance appraisal, training and development, HR planning, recruitment, career planning, negotiations. It is very important for a bank to clearly identify its human information requirements before implementing HRIS. This would enable to decide the appropriate level of sophistication of HRI and would lead to optimal utilization of scarce resources. HRIS database should be used as a single source of all information. This would lead to the development of an integrated HRIS platform for the whole organization. Such integrated platform is preferable over singular optimization as it leads to effective information exchange between HR processes and 
HRIS IT platform. The success of banks largely depends on the intellectual development of the employees. Along with intellectual development of the knowledge worker, technical infrastructures of the bank must be ensured to enhance the effectiveness of the employee and the bank. Generally, the banking profession in Ethiopia is recognized with standardized salary scale, higher social status and dignity. As can be found from the study, human resources in banks were enjoying comparatively better facilities under the rules of banking industry. Employees of the bank getting good number of bonus and compensation, including salary grade, leave facilities, housing facilities, gratuities, provident funds, and losses of accident or death of employees etc. The employees in the Commercial Bank of Ethiopia are more satisfied with salary scale, job position, promotion scheme, working environment but very worried about the system about information sharing of human Resource and their difficulty to store, retrieve, share and maintain information. Most of the employees are less satisfied with HRIS practice, Time spent on it, performance measurement. Bank should decentralize their HR activities in all Districts and develop strong HRIS practices. Authority and responsibility should be properly distributed to all staffs and the HR system fully supported by DBMS (Data base management system). Bank should give some significant power and role to District HR to systematize there activity in order to access all the necessary information.HR department in commercial bank of Ethiopia at District level are almost manual it has its own impact and create ineffectiveness. The proper empowerment of HR department means their participation in preparing management policies, plan and program, forecasting demand and supply of human resources and in policy formulation and implementation with the support of technology is crucial one. This will help to recruit and maintain skilled, knowledgeable and well performed workforce to meet current and future organizational as well as individual needs.

\section{CHALLENGES IN IMPLEMENTATION OF HRIS}

The effective implementation of HRIS requires re-engineering of business processes, which our banks find hard to adopt. The banks' employees lack sufficient training to adopt the new system. At the same time, the information systems of most of the banks are disparate, which reduces their efficiency. So even if commercial bank of Ethiopia implement HRIS, it is a fairly long and peace-meal exercise. It is very important to view the implementation of HRIS as a whole to ensure system integrity. Despite the contributions of IT department to banking operations in Commercial Bank of Ethiopia, IT has not been fully explored in all dimensions, particularly in human resource department. Most districts human resource practices are performed by manually operates because of lack of implementation. So the commercial bank of Ethiopia has not fully integrated aspect human resources. In addition to the above fact, lack of consecutive training on the area under studied is no sufficient so it creates major drawback through practice.

\section{RECOMMENDATION}

On the basis of the findings of the study the following recommendations are made for better HRI practice in the Commercial Bank of Ethiopia, Dessie District.

- Provision should be created to employ professional staffs having graduate and/or postgraduate degrees in information technology at IT department of banks to enhance 
information sharing, manipulation, maintain and store information that emphasis in the selection and recruitment process of employees.

- To develop HRIS, the commercial bank of Ethiopia should undertake different HRD programs including continuing education and training, ICT-orientation, career development, etc. Banks "e have good number of bright employees and it should create opportunities for employee's higher studies with fellowship/scholarship at home and abroad.

- Commercial Bank of Ethiopia should empower human resource for further handling its information for recruiting, selection, screening of its staff on day to day basis.

- Commercial Bank of Ethiopia should organize seminars, workshops, conferences, different short courses, and training programs on financial matters, current issues, software up gradation on regular basis that would definitely help to develop knowledgeable manpower, create awareness and change mental attitudes among the employees.

- Commercial Bank of Ethiopia should allocate sufficient budget and sends competent employees to international conferences and seminars to prepare them for the competitive knowledge market of 21st century.

- Commercial Bank of Ethiopia should apply standard techniques for employees ${ }^{e e}$ job evaluation, performance measurement and audit as a routine work. On the basis of the result, their duties and responsibilities should be redesigned and restructured. Because it will reduce the repetitive work and reduce monotonous environment.

- The commercial bank of Ethiopia need have to invest more money on IT technology to improve its human resource practice thoroughly.

- Commercial Bank of Ethiopia need have to have feasible HRIS programs that help districts human resources departments to easily recruit, train staffs and manipulate information. But it is essential to empower the department for handling different issues in HRM in banks. The department should be incorporated with well-organized HRIS (human resource information systems) and modern IT facilities.

- The Top management should have to focus on the major roles of HRIS system is to improve communication between HR and other departments, facilitate effective decision making and make effective decisions and gain a competitive advantage for the organization.

\section{LIMITATION OF THE STUDY}

The study is bounded only to the area of quality of Human resource information in CBE, Dessie District. It doesn't touch other department (Areas) in Dessie District like Compliance Audit, loan section because of time constraints. So the paper point out focus areas in quality information sharing, storing and retrieving of data in Commercial Bank of Ethiopia, Dessie District, Human Resource and so staff member and management of the District and Head office Organs got few ideas on the area under studied.

\section{REFERENCE}

[1] Annual Report, (June 2014), A Bilingual Magazines Published by the Communications of Commercial Bank of Ethiopia, Vol. 3, No 4. pp.24. 
[2] Beadles, Nicholas, C. M. (2005). The Impact of Human Resource Information System: an Exploratory Study in Public Sector. Communications of IIMA, 5(4), 39-46.

[3] Dessler, G., Griffiths. And B. Lloyd-Walker (2004), Human Resources Management, 2nd ed. French's Forest, New South Wales: Pearson Education Australia, pp. 97-99.

[4] Dr. Harman Preet Singh, Dr.Sunita Jindal, Sekl Abdul Samine, June 2011, Special Issue of the international Journal of the computer, the intern ate \& management, V0119, No.SPI, New Delhi, India).

[5] Hendrickson R. Anthony (2003). Human Resources Information Systems: Backbone

[6] Longneck-Hall, Mark L. and Moritz Steve (2003), "The Impact of e-HR on the Human Resource Management Function”, Journal of Labor Research. 24(3), pp. 365-379.

[7] Mathis R.L. and Jackson J.H. (2002), Human Resource Management, 10th edition, USA: Thomson learning, pp. 179 -207.

[8] Martinsons, M. G. (1994). Benchmarking human resource information systems in Canada Kong. Information \& Management, 26, 305-16.

[9] Martin sons, M. G. (1994). Benchmarking human resource information systems in Canada and Hong Kong. Information \& Management, 26, pp 305-16.

[10] Quarterly Commercial Bank of Ethiopia Informer Magazines, (May 2014), Vol. 4, No 5, pp 08.

[11] Special Issue of the International Journal of the Computer, June 2011, the Internet and Management, Vol. 19.

[12] Tannenbaum S.I. (1990), "HRIS: User Group Implications”, Journal of Systems Management, 41(1), pp. 27-32.

[13] Technology of Contemporary Human Resources. Journal of Labor Research, 24(3), pp 382-394, Journal of Business Studies Quarterly, 2012, Vol. 3, No. 4, pp. 77-91. 